\title{
Perspectives of Dendrimer-based Nanoparticles in Cancer Therapy
}

\author{
RICARDO I. CASTRO ${ }^{1,2}$, OSCAR FORERO-DORIA $^{3}$ and LUIS GUZMÁN ${ }^{4 *}$ \\ ${ }^{1}$ Multidisciplinary Agroindustry Research Laboratory, Universidad Autónoma de Chile, 5 Poniente, 1670, Talca, Chile \\ ${ }^{2}$ Escuela de Obstetricia y Puericultura, Facultad de Ciencias Biomedicas, \\ Universidad Autónoma de Chile, 5 Poniente, 1670, Talca, Chile \\ ${ }^{3}$ Instituto de Química de Recursos Naturales, Universidad de Talca, Avenida Lircay, s/n, Casilla 747-721, Talca, Chile \\ ${ }^{4}$ Departamento de Bioquímica Clínica e InmunoHematología, Facultad de Ciencias de la \\ Salud, Universidad de Talca, Avenida Lircay, s/n, Casilla 747-721, Talca, Chile
}

Manuscript received on August 18, 2017; accepted for publication on October 21, 2017

\begin{abstract}
Currently, cancer is the second most common cause of death in the United States, exceeded only by heart disease. Chemotherapy traditionally suffers from a non-specific distribution, with only a small fraction of the drug reaching the tumor, in this sense, the use of dendrimers incorporating drugs non-covalently encapsulated inside the dendrimer or covalently conjugated have proven to be effectives against different cancer cell lines. However, at present the dendrimers used as drug-carriers still do not meet the necessary characteristic to be considered as an ideal dendrimer for drug delivery; high toxicity, bio-degradability, low toxicity, biodistribution characteristics, and favorable retention with appropriate specificity and bioavailability have not been fully covered by the current available dendrimers. However, the development and study of new dendrimers drug-carriers continues to be an important tool in the cancer therapy as they can be functionalized with varied ligands to reach the tumor tissue through the different body barriers in the body with minimal loss of activity in the bloodstream, have the ability to selectively kill tumor cells without affecting the normal cells and most important with a release mechanism controlling actively. Given the continuous efforts and research in this area of interest, we presented in this review the work done with a special emphasis on the development of dendrimers as a major tool in the combination with drugs, as a potential adjunctive agent in anticancer therapy.
\end{abstract}

Key words: dendrimers, cancer therapy, pharmacodynamics, nanoparticles.

\section{INTRODUCTION}

Cancer is a major cause of deaths and is expected to become a major source of morbidity and mortality during coming decades. In 2012, an approximated

Correspondence to: Luis Guzmán

E-mail:1guzman@utalca.cl

* Contribution to the centenary of the Brazilian Academy of Sciences. of 14.1 million people were diagnosed with cancer, and about 8.2 million people died of cancer (Ferlay et al. 2015). Currently, cancer is the second most common cause of death in the United States, with lung cancer, liver cancer and stomach cancer being the most common cause of death, exceeded only by heart disease (American Cancer Society 2011).

Cancer is an uncontrolled cell proliferation caused by physical, chemical, genetic or biological 
factors. There are dozens of ways in which the disease occurs but its basic pathophysiology comprises aberrations at any point in the molecular machinery that governs the cell cycle and therefore cause the deregulations of this. The progression at a genetic level is the accumulation of successive mutations, since a single somatic mutation is not enough to develop a cancer. In order for a tumor to appear, it is necessary to lose the multiple controls exerted by the three gene categories: oncogenes, cancer suppressor genes and apoptosis regulatory genes; the accumulation of these mutations is a consequence of the genetic instability of the abnormal cells (Alberts 2004).

Among the proteins that regulate the cell cycle and that are altered can be mentioned the Cyclin $\mathrm{D}$, which has been increased in multiple types of cancer, such as stomach or esophagus (Golias et al. 2004), Cyclin B increases in cases of human papillomavirus (HPVs, human papilloma-viruses) 16 or 18 , which are the main cause of cervix cancer in women, the oncoprotein E7, which, like the cyclin D / CDK complex, can block the function of the retinoblastoma protein, a tumor suppressor protein that is altered in many types of cancer by promoting the cell cycle (Kim and Zhao 2005), Cells overexpressing c-myc are resistant to growth arresting effects promoted by the transforming growth factor $\beta$ (TGF $\beta$ ) which induces the expression of p15, p21 and p27 (the same c-myc repressed CKIs). This situation is also found in approximately $80 \%$ of cervical tumors (Gartel and Shchors 2003), and the p53 gene is mutated in half of the known human cancers (of liver, skin, lung, etc.). Myeloid leukemias are part of the other fifty percent where there are no mutations in this gene (Ryan et al. 2001).

Nowadays, targeted therapy is gaining importance due to its specificity towards cancer cells while sparing toxicity to off-target cells. Targeted therapy involves developing drugs that block cancer cell proliferation, promote cell cycle regulation or induce apoptosis or autophagy and targeted delivery of toxic substances specifically to cancer cells to destroy them (Padma 2015, Gerber 2008). These highly specific agents should be capable of exerting its effect on individual proteins or pathways, either over-expressed or aberrants in tumors, this specificity to eliminate tumor cells is important to avoid toxicities associated with traditional chemotherapies, while resulting in improved antitumor efficacy (Blanco et al. 2011).

Chemotherapy traditionally suffers from a nonspecific distribution, with only a small fraction of the drug reaching the tumor, from this point of view the pharmacokinetic properties known as absorption, distribution, metabolism and elimination (ADME), determine the amount of the drug and/or its active metabolite reaching the tumor (Damia and Garattini 2014). The ADME are mediated by drugmetabolizing enzymes and transporters expressed in different tissues including small intestine, liver and kidney. In particular, xenobiotic-metabolizing enzymes such as cytochrome $\mathrm{P} 450$ isoforms play a critical role in the metabolic elimination of drugs, and transporters such as ATP binding cassette $(\mathrm{ABC})$ and solute carrier (SLC) transporters have high impact on drug absorption, distribution and excretion. The interactions between drugs and enzymes/transporters ultimately determine the pharmacokinetic properties and subsequently influence the pharmacodynamics (Ai-Ming and YuZhuo 2012).

Today, it is well known that injectable materials undergo sequestration by the mononuclear phagocyte system (MPS), which is a system composed of monocytes and macrophages and organs like the liver, spleen, lungs and bone marrow. Indeed, once in the bloodstream, surface nonmodified of nanoparticles are rapidly opsonized and massively cleared by the fixed macrophages of the MPS organs (Gustafson et al. 2015, Peer et al. 2007). As a result, the drugs are accumulated in healthy organs, with its inherent toxicity, drawing a 
fine line between tolerability and severe morbidity, as is the case of doxorubicin, a DNA intercalating drug that lead to cardiotoxicity (Olson and Mushlin 1990).

In addition, cancer cells maintain a unique $\mathrm{pH}$ gradient, creating a unique environment around them, it is more acidic extracellularly and more alkaline intracellularly. The tumor microenvironment increases tumor's fitness by blunting the immune system, activating endogenous immunosuppressive strategies and inhibiting the growth of the normal cell population. Moreover, the tumor microenvironment disables the activities of several chemotherapeutic agents resulting in resistance and failure in drug response either through disturbing drug partitioning, sequestering it intracellularly or through induction of multidrug resistance expression (Alfarouk et al. 2015). All these factors prevent the healing potential of the anticancer drugs, justifying the search for more effective ways to release the drugs into the tumor (Blanco et al. 2011).

With these limitations in mind, Paul Ehrlich coined the term "magic bullet" to chemotherapy (Strebhardt and Ullrich 2008). There are many different types of nanoparticles used in medical therapy as for example nanoparticles of $\mathrm{Fe}_{4}\left[\mathrm{Fe}(\mathrm{CN})_{6}\right]$ (Long et al. 2016), nanotubes (Li et al. 2017), liposomes, polymer-drug conjugates and others. The liposomes and polymer-drug conjugates were developed in the ' 60 s and ' 70 s (Duncan 2003); these are now the main platforms in the field of nanomedicine (Ferrari 2005), emerging as a research area, which could have profound effects on the current paradigms that exist in various disease states. The scientific community has embraced the possibilities of nanomedicine in diseases such as cancer, whose optimal treatment has eluded researchers for decades due to the use of highly toxic compounds which are non-specific to cancer cells, resulting in an excessive toxicity to the surrounding healthy cells and, for many patients, the cancerous cells are discovered only after they have spread too extensively for treatment to significantly improve life expectancy and quality of life (LaRocque et al. 2009).

Given the continuous efforts and research in this area of interest, we presented in this review the work done with a special emphasis on the development of dendrimers as a major tool in the combination with drugs, as a potential adjunctive agent in anticancer therapy.

\section{DENDRIMERS}

Dendrimers or dendritic molecules correspond to molecules with a central core and repeated branches (Figure 1). They can be classified by its form as polymers, hyperbranched polymers or brush-polymers and also can be classified by their molecular weight as low or high molecular weight (Morikawa 2016).

Its structure provides unique opportunities by chemical conjugation (dendrimer-drug), the supramolecular structure of dendrimer-drug complexes is formed based on different interactions as electrostatic and hydrophobic/hydrogen-bond, among others, or encapsulation, within the central cavity and/or within the multiple channels between the dendrons (Blanco et al. 2011, Lee et al. 2005). The applications of these molecules is quite broad, ranging from drug delivery applications, wherein dendrimer nanoparticles are combined with therapeutics and targeted to specific tissues or gene delivery which works similarly to drug delivery but combining the dendrimer nanoparticles with nucleic acids (Svenson 2009), providing advanced and alternative solutions, as a drug carrier due to the specific physicochemical characteristics, such as polarity, net charge, solubility in water, among others (Satsangi et al. 2015). 


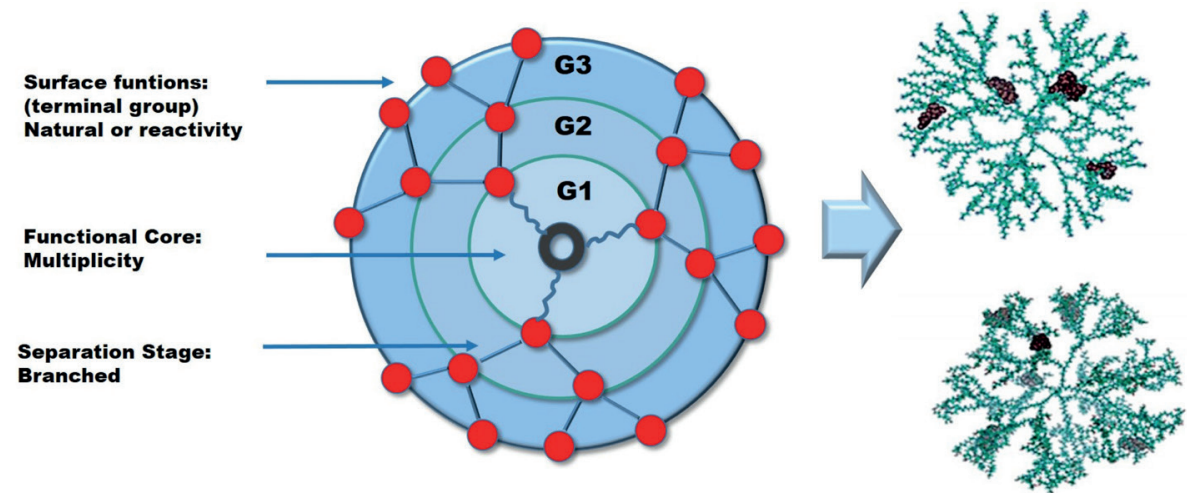

Figure 1 - Architectural components of dendrimers.

\section{STRUCTURE}

These molecules are characterized by techniques such as Nuclear magnetic resonance (NMR) of proton $\left({ }^{1} \mathrm{H}\right)$ and carbon $\left({ }^{13} \mathrm{C}\right)$, Matrix Assisted Laser - Desorption Ionization - Mass Spectrometry (MALDI-MS), Thermogravimetric analysis (TGA), Differential scanning calorimetry (DSC), Scanning electron microscope (SEM), Transmission electron microscopy (TEM), rheology and scattering techniques (Valdes et al. 2016) and have attracted much attention because of their structures, as highly branched macromolecules, possessing symmetrical architecture with a globular shape, in which, all the bridges emerge radially from a core point with a regular branching pattern and with repeated units, each of which contributes to a new branching point (Frechet 2002, Urzua et al. 2016).

Two synthetic methodologies have been used for dendrimers, using reactions of amides formation, esterification and nucleophilic addition: the divergent approach method (Newkome et al. 1985, Tomalia et al. 1985), described by Tomalia et al. (1986), in which the growth begins in the core and proceeds radially toward the periphery of the dendrimer, and the convergent approach described by Hawker (Grayson and Frechet, 2001, Hawker and Frechet 1990), where the dendrimer grows from the periphery to the indoor. The two approaches are complementary and neither of them generally is better than the other, the choice of the synthetic method used has usually been justified by the characteristics of the target molecule, the chemistry available for growth, and the specific building blocks used in the construction of the dendrimer (Frechet 2002).

The branching units are described by generation, beginning with the central core as generation $(-0.5)$, this is the intermediate generation that then is transformed into the generation 0 (G0) and increases with each successive addition of the branch points (G1, G2, etc); each successive generation increases the number of terminal groups exponentially. Thus, the G5 dendrimer has four generations on branch points emanating from the central core. The dendritic macromolecules increase linearly in diameter, adopting a globular shape with each increased generation of the dendrimer (Sampathkumar and Yarema 2005, Svenson and Tomalia 2005, Wolinsky and Grinstaff 2008).

\section{NANOPARTICLE INTERACTION WITH CELL MEMBRANES AND BIOCOMPATIBILITY}

The interaction of nanoparticles and biological membranes is a complex process, difficult to understand in detail due the heterogeneity of both. Despite this obstacle, there is strong interest in discovering the general principles that govern the interactions and the specific details between polymers and particular cell types, offering new 
applications of nanoparticles for drug and gene delivery (Leroueil et al. 2007).

Many ideas have been raised about the size of the dendrimer and the ability of terminal groups associated with lipid molecules, based on the assembly of dendrimer-lipid vesicles. The radius of the lipid heads (L) in contact with the surface of the dendrimer and the number of terminal groups of the dendrimer (P) appear to be factors in the formation of the pore. For example, poly amide amine (PAMAM) generation 7 (G7) dendrimers supports low radios (L/P) allowing the formation of stable vesicles dendrimer-lipid (Mecke et al. 2005).

In separate studies, it was shown that cationic PAMAM dendrimers leads to the formation of a single pore in the membrane fluid phase, while the existence of a gel phase in the plasma membrane is not affected by the presence of these dendrimers, suggesting that depending on the phase of the lipid bilayer could impact in cellular uptake studies under experimental conditions such as size, chemical functionality, and charge of the dendrimer (Mecke et al. 2005, Wolinsky and Grinstaff 2008).

The concept of architecture of the dendrimer and the creation of pores in the lipid bilayer was expanded to a range of linear and dendritic polymers, commonly polycationic dendrimers investigated in in vitro drug delivery applications, including poly-L-lysine (PLL), polyethyleneimine (PEI) diethylaminoethyl dextran (DEAE-DEX), and PAMAM, which were compared against neutrally charged polymers, including polyvinyl alcohol (PVA) and polyethylene glycol (PEG), in vitro. In this regard, the charge density of the polymers was found to have a significant impact on the permeability of the membrane, with the most densely loaded polymer (PEI), releasing the biggest amount of cytosolic enzymes outside the cell, as well as providing transport of supravital dye. The ability of PAMAM to increase cell membrane permeability was attributed to the spherical architecture necessary to promote interactions between dendrimers and lipid molecules. Meanwhile, PVA and PEG had no impact on membrane permeability (Hong et al. 2006, Wolinsky and Grinstaff 2008).

Seib et al. (2007) studied the effect of the structure in the cellular mechanism of absorption velocity in linear and branched PEI's, and PAMAM dendrimers (G2, G3 and G4). The G4 PAMAM dendrimers showed the strongest rate of absorption, followed distantly by the branched PEI, PEI linear, G3 and G2 PAMAM in a decreasing magnitude of internalization. The G4 PAMAM and branched PEI were internalized mainly by cholesteroldependent pathways, whereas the absorption of linear PEI, was independent of cholesterol and clathrin pathways, suggesting that the dendrimer architecture somehow affect cellular internalization (Seib et al. 2007, Wolinsky and Grinstaff 2008).

For its part, the amino groups of some dendrimers influence the biological membranes due to the electrostatic interactions, because of its high positive charges and negative charges of cell membranes (Niederhafner et al. 2008, Tomalia et al. 2007). However, older generations of dendrimers terminated in amino groups (over G3) causes destructive interactions with membranes, which lead to cell lysis and high toxicity. On the other hand, the negatively charged dendrimers (surfaces with carboxylic acids) do not interact with most cell membranes and thus do not have a generation-dependent toxicity. When uncharged dendrimers are studied, their cytotoxicity depends on the polarity of the surface of the terminal groups. Dendrimers, with polar membranes non-invasive as PEG groups have a non-toxic behavior. In contrast, non-polar groups such as lipids interact with the cell membrane by hydrophobic interactions; this results, in some cases to cytotoxic dendrimers. Lipids (especially glycosphingolipids) may also have a positive influence, because they can provide the dendrimers with immunostimulatory properties. The biodistribution, clearance, and toxicity are 
closely related to particle size of the nanoparticles (Sebestik et al. 2011).

In general, one can observe that the toxicity of dendrimers is dependent on the chemistry of the core, but is more strongly influenced by the nature of the surface of the dendrimer. For example, the cytotoxicity measured by the $3-(4$, 5-dimethylthiazolyl-2)-2, 5-diphenyltetrazolium bromide) assay (MTT assay) of a library of dendrimers based on melamine surfaces, including amines, guanidines, carboxylate, sulfonate, phosphonate, or PEGylated, showed that cationic dendrimers were much more cytotoxic than anionic dendrimers or PEGylated (Chen et al. 2004). Similarly, quaternaries PAMAM-OH showed lower levels of cytotoxicity that PAMAM- $\mathrm{NH}_{2}$, given that the inner cationic charges were sealed by the surface of the hydroxyl groups (Lee et al. 2003). The surface modification of G4 PAMAM with lysine or arginine leads to increased toxicity compared to G4 PAMAM native, when were incubated in HepG2 cells or human embryonic kidney cells 293 (Choi et al. 2004), this was attributed to increased charge density and molecular size. It has also been found that anionic PAMAM dendrimers G1.5 - 9.5 and dendrimers DAB with surfaces $-\mathrm{COOH}$ are not cytotoxic in HepG2, CCRF and B16F10 cells, at a concentration of up to $5 \mathrm{mg} / \mathrm{mL}(72 \mathrm{~h}$, MTT assay). SEM and B16F10 cells exposed to these anionic dendrimers showed no morphological changes (Malik et al. 2000). A potential toxicity of the dendrimer core is achieved when these are presented to cells with low generation dendrimers, due to its open molecular structure. In addition, low generation dendrimers, have a surface more accessible to end groups, which in the older generation is sterically hindered due to the high accumulation of terminal groups on the surface, the increase in branching (generation) and high surface coverage with biocompatible end groups like PEG are being widely used to create less toxic dendrimers (Duncan and Izzo 2005).
Regarding in vivo studies Roberts et al. 1996, administered G3, G5 and G7 PAMAM dendrimers to groups of five male Swiss-Webster mice each, injecting $5 \times 10^{-6}, 5 \times 10^{-5}$ or $5 \times 10^{-4} \mathrm{mmol} / \mathrm{kg}$ of each compound. The dendrimers were administered as a single dose or repeated once a week for 10 weeks and the observations were made by either 7 days or for a period of 6 months. In this study, there were no reported changes in behavior or weight loss in mice at 2 hours after administration, however, three animals died (injected with G7 PAMAM). In a multiple dose study, a degree of liver cell vacuolation was observed during histopathology that could be consistent with a lysosomal storage problem. Future studies are needed to corroborate these results (Duncan and Izzo 2005, Roberts et al. 1996).

In turn, three daily doses of PAMAM G3.5 administered to mice intraperitoneally at a daily dose of $95 \mathrm{mg} / \mathrm{kg}$ did not cause adverse changes on the weight of $\mathrm{C} 57$ mice, which carrying the B16F10 tumor line (Malik et al. 1999). When the melanin PEGylated dendrimers was injected into $\mathrm{C} 3 \mathrm{H}$ male mice in a single dose of $2.56 \mathrm{~g} / \mathrm{kg}$ intraperitoneal or $1.28 \mathrm{~g} / \mathrm{kg}$ intravenous, non-toxicity or mortality was observed. In addition, after $24 \mathrm{~h}$ of intravenous administration and $48 \mathrm{~h}$ of intraperitoneal injection, no changes were observed in blood parameters (blood urea nitrogen levels or transaminases); however, a longer period of observation is needed to provide a more accurate response (Chen et al. 2004).

The applications of PAMAM dendrimers in drug delivery are limited given its inherent cytotoxicity, correlated with the generation of the dendrimer and the surface area of the dendrimer (Yellepeddi et al. 2009). Therefore, their toxicity could be reduced significantly by changes in its surface. Conjugation with PEG significantly decreased the cytotoxicity in vitro and in vivo, of G5 and G6 PAMAM dendrimers (Mishra et al. 2009, Qi et al. 2009). 


\section{PHARMACOKINETICS}

Vehicles transporting polymeric drugs can be designated as nanoparticles that release encapsulated drugs via a surface diffusion or swelling, in a time or in a dependent-conditions manner. The release of the active agent may be constant over a long period of time, cyclical over a period of time, or can be triggered by environmental events or other external events (Kost and Langer 2001), such as changes in $\mathrm{pH}$ (Shmeeda et al. 2006, Yin et al. 2006) and temperature (Furgeson et al. 2006), like folate-conjugated liposomes which targeting the up-regulated folate receptors of cancer cells or Poly(N-isopropylacrylamideco- propylacrylic acid) copolymers that respond to temperature and $\mathrm{pH}$. Other agents respond to the presence of an analyte such as glucose, composed of solid, particulate insulin, incorporated into an ethylene-vinyl acetate copolymer (EVAc) matrix (Brown et al. 1996). In general, polymer systems for controlled release should provide a release drug level in an optimum range over a long period of time compared to other methods of drug delivery. This increases the effectiveness of the drug and maximizes the patient's confidence, while improving the possibility of using highly toxic drugs, poorly soluble or relatively unstable. The first consideration in drug delivery is to achieve more effective therapies while eliminating the potential for overdose or inadequate dose (Alexis et al. 2008).

Another advantage of using controlled release systems include the maintenance of drug levels within a desired range, the need for fewer administrations, optimal use of the drug in question, and increased patient confidence. This is particularly relevant for cancer therapy, in which treatment effectiveness is directly related to the ability to kill cancer cells while affecting the fewest amount of healthy cells possible (Alexis et al. 2008).
As a general rule, for any carrier polymer to be used for parenteral applications is essential that this, be non-toxic, non-immunogenic, and preferably biodegradable. This should show a distribution in the body enabling the proper orientation to reach the desired tissue and away from sites that could be toxic (Duncan and Izzo 2005).

The need for biodegradable dendrimers emerged as a strategy to produce the desired high molecular weight carrier to reach a high accumulation and retention in tumor tissue while, in turn, allow the rapid and safe removal of the dendrimer fragments in the urine and avoid the nonspecific toxicity. The biodegradable dendrimers are usually prepared by inclusion of ester groups in the polymer structure, which will be chemically hydrolyzed and/or enzymatically cleaved by esterases in physiological solutions (Lee et al. 2006, Morgan et al. 2006). Grinstaff, compared the rate of degradation of dendrimers G1 polyester [poly (glycerol-succinic) PGLSA] in the presence of acid, base and esterases, with polyester-amide dendrimers (G2) and polyester-ether (G3) to identify factors that control its kinetics degradation in physiological conditions (Grinstaff 2002). The results of this study showed that the polyesterether dendrimers were the fastest to degrade due to the increased hydrolytic susceptibility compared to polyester and polyester-amide derivatives. Consequently, the following four factors seem to control the rate of degradation of the dendrimers: 1) the chemical nature of the bridges connecting the monomer units with ester bonds, being the most susceptible to hydrolysis compared with the amide and ether bonds, 2) hydrophobicity of monomer units, where more hydrophilic polymeric units (e.g., glycerol, lactic acid and succinic acid) result in rapid degradation compared to the hydrophobic monomers (e.g., phenylalanine and alkyl amines), 3 ) the fact that dendrimers with large sizes and molecular weights are degraded more slowly compared to smaller given the tight packing of its 
surface, which effectively seals the hydrolysable groups, and 4) the susceptibility to cleavage of internal and external structure of the dendrimer, due to the inside hydrolysis leads to a faster degradation (Grinstaff 2002).

\section{DRUGS CONJUGATION TO DENDRIMERS}

The drug delivery systems based on polymers are designed to improve pharmacokinetics and biodistribution of thedrug and/orprovidea controlled release kinetic in the target cell (Allen and Cullis 2004). The ideal dendrimer carrier should exhibit high water solubility, high drug carrying capacity, biodegradability, low toxicity, biodistribution characteristic, and favorable retention with appropriate specificity and bioavailability. In the release of drugs based on dendrimers, the drug is non-covalently encapsulated inside the dendrimer or covalently conjugated to form a macromolecular prodrug (Wolinsky and Grinstaff 2008).

\section{DENDRIMER-DRUG COMPLEX}

Buhleier et al. (1978) studied guest molecules trapped in branched polymers, representing an early form of physical encapsulation of poorly soluble drug molecules in the spaces of dendrimers to improve its water solubility and controlled release profile (Bhadra et al. 2003, Morgan et al. 2006). The inclusion of hydrophobic molecules within dendrimers is typically achieved by simple mixing a polymer solution and drugs, where the hydrophobic drug associates with the nonpolar center via hydrophobic interactions (Morgan et al. 2003, Patri et al. 2005). As a result of the physical interface between the molecules and the dendrimer transporter (Figure 2), the release of encapsulated molecules in the aqueous environment is passively controlled by a range of non-covalent interactions including hydrophobic forces, hydrogen bonds, steric hindrance and Van der Waals electrostatic interactions (Medina and El-Sayed 2009, Mukherjee et al. 2015).

In this regard, camptothecin, a class of wellestablished anticancer drug with a very low solubility in water, was successfully encapsulated in a polyester dendrimer carboxylate terminated G4.5 to form a dendrimer-drug complex. All complexes showed much lower $\mathrm{IC}_{50}$ on cancer cells than free camptothecin (1.2 to 7.1 times the activity)

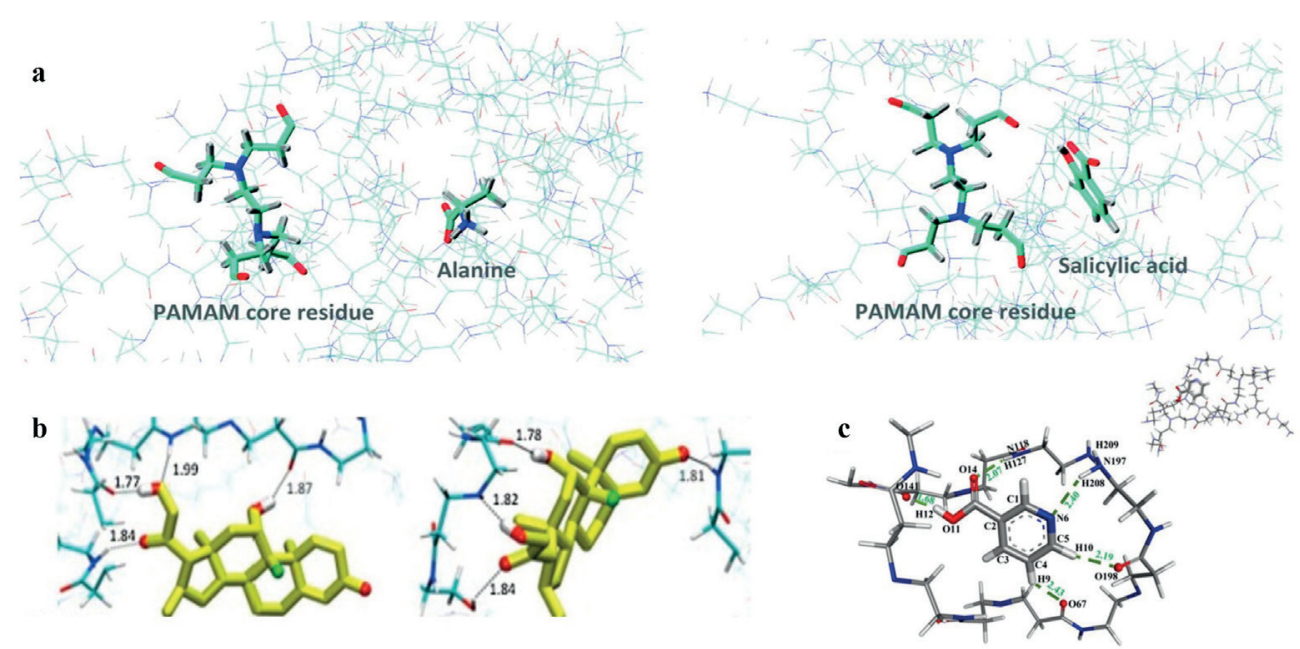

Figure 2 - Proposed model for a complexation between a drug and dendrimers by hydrogen bonds, steric hindrance, electrostatic interactions and Van der Waals interactions. a) PAMAM dendrimer Alanine complex and PAMAM dendrimer - Salicylic complex (Maingi 2012), b) Interaction affinity of the PAMAM-PCL/dexamethasone system by hydrogen bonds (Avila-Salas 2017), c) Representation of hydrogen bonding interactions between Nicotinic Acid and PAMAM G1 (Badalkhani-Khamseh 2017). 
depending on the cell line used. The cellular uptake of the complex by MCF-7 cells was significantly higher (about 16 times) than those of the free drug. In addition, was observed a greater retention time of the drug inside the cell in the presence of dendrimers than in those in which the drug was free (Cheng and Xu 2008, Morgan et al. 2005).

Moreover, melanin-based dendrimers have been used to solubilize and reduce the toxicity of the anticancer drug methotrexate (MTX) and 6-mercaptopurine and reduce the toxicity of these drugs. In $\mathrm{C} 3 \mathrm{H}$ mice, to which were administered subchronic doses of dendrimers with encapsulated drugs, were measured the levels of alanine amino transferase (ALT) to determine the hepatotoxicity, the ALT levels decreased by $27 \%$ for the dendrimer encapsulating MTX and 36\% for the dendrimer encapsulating 6-mercaptopurine in comparison to animals receiving the drug alone (Neerman et al. 2004). The major drawback of these delivery systems is the lack of controlled release kinetics of the drug, with most systems, releasing its load in the course of several hours. For this reason, dendrimers systems that encapsulate drugs could be better used via direct intratumoral injection (Wolinsky and Grinstaff 2008).

\section{DENDRIMER-DRUG CONJUGATES}

An alternative strategy for the use of dendrimers as carriers of anticancer drugs is making most of its well-defined multivalent structure in covalent bonds with the drug at its periphery. These examples are shown in Table I, the release of the drug can be adjusted by applying concepts of selective sites with degradable spacers between the drug and the dendrimer peripheral groups. Moreover, the burden of the drug to the dendrimer can be adjusted by varying the number of groups on the periphery of the dendrimer (Tekade et al. 2009).

TABLE I

Dendrimer - drug interactions on cancer therapy.

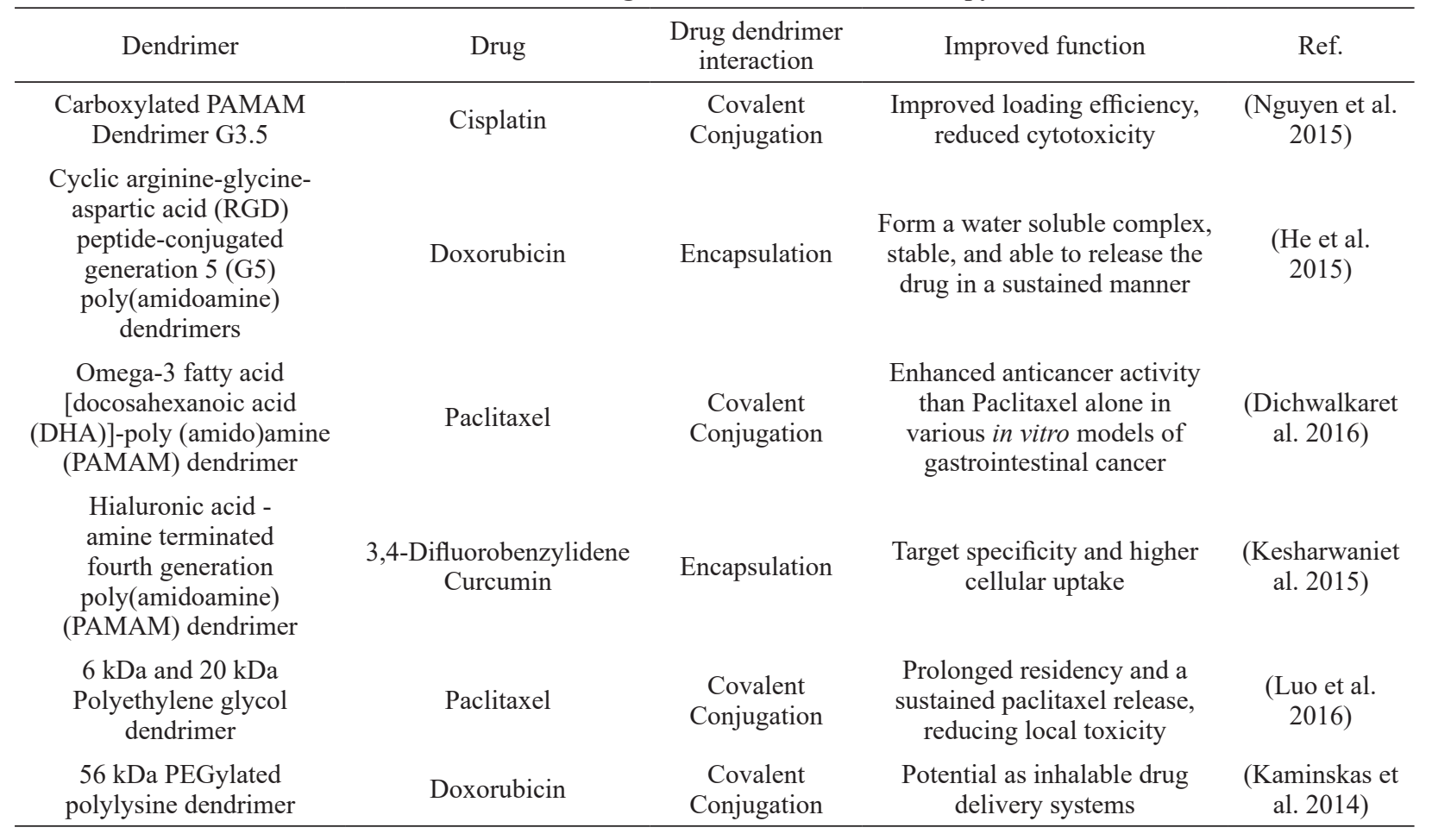


The utility of these degradable spacers was demonstrated by Greenfield et al. (1990) who use $\mathrm{pH}$-sensitive bonds to adriamycin immunoconjugates. The conjugate was stable at physiological $\mathrm{pH} 7.4$, but was found to undergo hydrolysis when was absorbed into the polymer by endocytosis and driven to subcellular organelles moderately acids such as endosomes and lysosomes. Keeping this model in mind, Ihre et al. (2002) reported the design and synthesis of a dendritic polyester system based on monomers 2,2bis (hydroxymethyl) propanoic acid as a potential drug carrier. The drug doxorubicin was attached via $\mathrm{pH}$-sensitive binding, demonstrating the feasibility of using these polyester dendritic structures to produce polymer-drug conjugates capable of releasing drugs to determined $\mathrm{pH}$ of cancer sites (Tekade et al. 2009).

In turn, hydroxyl-terminated G4 PAMAM in conjugation with paclitaxel through a union with succinic acid showed a significant increase in anticancer activity compared to free drug (10 times) (Khandare et al. 2006). Both conjugated, dendrimer-paclitaxel and PEG-paclitaxel, showed similar release profiles, across the membrane of cancer cells. The conjugate based on dendrimer had the highest anticancer activity than that based on PEG (250 times), suggesting that the dendrimer increases the levels of absorption of paclitaxel while PEG molecules decrease absorption by increasing the molecular weight of the drug. The dendrimers (carboxyl-terminated) conjugated with MTX via amide binding bridges was 3 to 8 times more potent than free MTX in MTX-sensitive cell lines (CCRF-CEM) and MTX-resistant (CEM/ MTX), respectively (Gurdag et al. 2006). The conjugate was even 24 times more active than free MTX in other MTX-resistant cells (CHO) (Cheng and $\mathrm{Xu} 2008)$.

\section{TARGETED CANCER THERAPY}

The vasculature of tumors is highly heterogeneous, ranging from vascular necrosis areas to densely vascularized areas in order to sustain an adequate supply of oxygen and nutrients to the growing tumor. Tumor blood vessels have several abnormalities compared with normal blood vessels, including a high proportion of proliferating endothelial cells with an aberrant basement membrane, increased tortuosity of blood vessels and pericytes deficiency (Jain 2001). The microvasculature has also shown an increased permeability, which is regulated in part by abnormal secretion of vascular endothelial growth factor, bradykinin, nitric oxide, prostaglandins and matrix metalloproteinases. The transport of molecules can occur through the tumor microvasculature by opening inter-endothelial junctions and trans-endothelial channels (Alexis et al. 2008, Jain 2001).

Ideally, an anticancer drug should be first (after administration), able to achieve the desired tumor tissue through penetration of the barriers in the body with minimal loss of volume or activity in the bloodstream. Second, after reaching the tumor tissue, the drug should have the ability to selectively kill tumor cells without affecting normal cells, with a release mechanism controlled actively. In principle, the drug release of nanoparticles in tumor tissues can be addressed in two ways: passive and active (Misra et al. 2010).

\section{PASSIVE DISTRIBUTION}

The passive distribution refers to the accumulation of the drug or drug carrier system in the desired location given physico-chemical factors or pharmacological (Misra et al. 2010). Therapeutic macromolecules including drug delivery systems based on dendrimers, exploit the pathophysiological pattern of solid tumors, particularly its discrete vasculature to preferentially extravasate and accumulate in tumor tissue in a process known as 
the effect of increased permeability and retention (EPR) (Maeda et al. 2000). The amount of the delivery system based on dendrimers, which accumulates in tumor tissue is influenced by the size, molecular weight and surface charge, which affects the residence time in the circulatory system, transport through the endothelial barrier, non-specific recognition and removal by the reticuloendothelial system (Haag and Kratz 2006). El-Sayed et al. (2002, 2003) study the effect of size, molecular weight, and surface charge on the permeability of PAMAM-NH ${ }_{2}$ dendrimers (G0G4) fluorescently labeled through the epithelial and endothelial barriers. Their data showed that the increase in the size/molecular weight of the dendrimer resulted in an exponential increase in the time of extravasation, through microvascular endothelium of the cremaster muscle in Syrian hamster (El-Sayed et al. 2001). A subsequent investigation by Kobayashi and Brechbiel (2005) studied the biodistribution of conjugates $\mathrm{G} 2-\mathrm{NH}_{2}$ to $\mathrm{G} 10-\mathrm{NH}_{2}$ functionalized with gadolinium, which were administered intravenously to normal mice. The results showed that the G2-G4 dendrimers functionalized with gadolinium was rapidly excreted in the urine after 3 minutes of intravenous injection while the G5 dendrimer and older generations showed a limited renal excretion due to its hydrodynamic volume. These studies show the influence of size and hydrodynamic volume of dendrimers in transport through the microvascular endothelium in vivo (Medina and El-Sayed 2009).

\section{ACTIVE DISTRIBUTION}

While the passive distribution of nanoparticles results in a preferential accumulation in tumors, an important non-specific binding of circulating nanoparticles also occurs in healthy organs. Therefore, a large area of research involves the functionalization of nanoparticles with specific fractions as monoclonal antibodies or ligands such as vitamins, carbohydrate residues or peptides, which identify and bind to receptors either overexpressed in tumors or in the endothelium associated to them, maximizing the localization and accumulation in the tumor (Blanco et al. 2011, Brigger et al. 2002, Huynh et al. 2009).

When it builds a nanoparticle with tertiary structure (consisting of the drug and the fragment directed against the tumor), certain factors must be considered to create efficient delivery systems. First, antigen or receptor should be expressed exclusively in the tumor cell and not expressed in normal cells. Second, antigen or receptor should be expressed uniformly in all tumor cells. Finally, the antigen or receptor should not be released into the bloodstream. The internalization of the conjugate after binding to the tumor cell is an important criteria in selecting the appropriate ligand (Misra et al. 2010). For example, folate is a small organic molecule with high affinity to the folic acid receptor, highly overexpressed in certain tumors (100 to 300 times above endogenous levels) (Ross et al. 1994). PEGylated dendrimers functionalized with folate containing 5-fluorouracil (5-FU), showed to have a high accumulation in tumor of $20.1 \%$ and $10 \%$ of the injected dose at 8 and 24 hours, respectively, resulting in a significant reduction of tumor growth (approximately 40\%) compared with nonfunctionalized controls after two injections (days 0 and 7) over 20 days (Blanco et al. 2011, Singh et al. 2008).

Other researchers have used different agents to reach the tumor including peptides to lead the drug delivery systems based on dendrimers to specific tumor receptors. Falciani et al. (2007) use neurotensin (NT) peptides to develop a dendrimer marked with NT carrying chlorine e6 (Cle6) and the chemotherapeutic agent MTX for various malignant tumors that express the receptor for NT, which includes carcinomas of colon, pancreatic, prostate and small cell lung. The treatment of mice carrying the tumor HT29 with conjugated 
dendrimers-MTX-NT for 20 days showed a reduction in tumor size in approximately one third in comparison to mice that received saline or conjugate without MTX, indicating the therapeutic benefit of the active approach.

Another example is that of Hildgen, who developed an inclusion complex MTX-dendrimer polyethercopolyester(PEPE)G2 for the treatment of brain tumors, which use as a ligand D-glucosamine disposed in the conjugate to link the transporters GLUT-1 highly expressed on the luminal side of endothelial cells of the blood-brain barrier and glioma cancer cells. In vitro studies showed that the conjugates MTX-PEPE exhibited 2 to 8 times greater accumulation in glioma cells, resulting in an effectiveness of 2 to 4.5 times greater than nonconjugated dendrimers (Dhanikula et al. 2008), other conjugated dendrimers used the tetrameric glycoprotein avidin to reach lectins differentially expressed on the surface of ovarian carcinoma cells (Xu et al. 2007). In turn, other constructs of PAMAM utilized the antibody J591 to reach the prostate-specific membrane antigen (PSMA), which is a glycoprotein expressed in all prostate cancer cells and the vasculature that supports it (Medina and El-Sayed 2009, Patri et al. 2004).

\section{CONCLUSIONS}

Nowadays, the ability to reach large numbers of drugs in specific tumor sites remains one of the greatest challenges in cancer therapy. In this regard, the use of dendrimers incorporating drugs as a complex, as polyester or melanin-based dendrimers carring camptothecin or MTX have shown good results in vitro using breast cancer cell line, nevertheless, the lack of controlled release kinetics of the drugs continue being one of the main challenges of this method. For its part, the use of dendrimers conjugated with drugs have arisen as an alternative to the lack of control in the liberation of drugs, applying concepts of selective sites with degradable spacers between the drug and the dendrimer peripheral groups, among them, dendritic polyester system based on monomers 2,2-bis (hydroxymethyl) propanoic acid attached to doxorubicin or hydroxyl-terminated G4 PAMAM in conjugation with paclitaxel through a union with succinic acid have shown great anticancer activity against ovarian carcinoma cells and acute lymphocytic leukemia cell line. However, no matter how the dendrimer transports the drug; an ideal dendrimer carrier should exhibit high water solubility, high drug carrying capacity, biodegradability, low toxicity, biodistribution characteristic, and favorable retention with appropriate specificity and bioavailability, characteristics that have not been fully covered by the current available dendrimers. Another important drawback is the heterogeneity of the cancer with cells that differ in their capacity of infiltration, their speed of growth, their capacity to form metastasis, their possibility of avoiding immune surveillance and other diverse characteristics, which makes it difficult to study the anticancer properties of the different dendrimers developed.

Despite the drawbacks mentioned above, the development and study of new dendrimers as drugcarriers continues to be an important tool in the cancer therapy as they can be functionalized with varied ligands to reach the tumor tissue through the different body barriers in the body with minimal loss of activity in the bloodstream, have the ability to selectively kill tumor cells without affecting the normal cells and most important with a release mechanism controlled actively.

\section{REFERENCES}

AI-MING Y AND YU-ZHUO P. 2012. Noncoding microRNAs: small RNAs play a big role in regulation of ADME? Acta Pharmacol Sin B 2: 93-101.

ALBERTS B. 2004. Essential cell biology. New York, NY Garland Science Pub, 860 p.

ALEXIS F, RHEE JW, RICHIE JP, RADOVIC-MORENO AF, LANGER R, AND FAROKHZAD OC. 2008. New 
frontiers in nanotechnology for cancer treatment. Urol Oncol 26: 74-85.

ALFAROUK KO ET AL. 2015. Resistance to cancer chemotherapy: failure in drug response from ADME to P-gp. Cancer Cell Int 15: 71.

ALLEN T M AND CULLIS PR. 2004. Drug delivery systems: entering the mainstream. Science 303(5665): 1818-1822.

AMERICAN CANCER SOCIETY. 2011. Cancer Facts and Figures 2011. Atlanta: American Cancer Society, 55 p.

AVILA-SALAS F ET AL. 2017. An experimental and theoretical comparative study of the entrapment and release of dexamethasone from micellar and vesicular aggregates of PAMAM-PCL dendrimers. Eur Polym J 93: 507-520.

BADALKHANI-KHAMSEH F, BAHRAMI A, EBRAHIMHABIBI A, AND HADIPOUR N. 2017. Complexation of nicotinic acid with first generation poly(amidoamine) dendrimers: A microscopic view from density functional theory. Chem Phys Lett 684: 103-112.

BHADRA D, BHADRA S, JAIN S AND JAIN NK. 2003. A PEGylated dendritic nanoparticulate carrier of fluorouracil. Int J Phar 257: 111-124.

BLANCO E, HSIAO A, MANN AP, LANDRY MG, MERICBERNSTAM F AND FERRARI M. 2011. Nanomedicine in cancer therapy: innovative trends and prospects. Cancer Sci 102: 1247-1252.

BRIGGER I, DUBERNET C AND COUVREUR P. 2002. Nanoparticles in cancer therapy and diagnosis. Adv Drug Deliver Rev 54: 631-651.

BROWN LR, EDELMAN ER, FISCHEL-GHODSIAN F AND LANGER R. 1996. Characterization of glucosemediated insulin release from implantable polymers. J Phar Sci 85: 1341-1345.

BUHLEIER E, WEHNER W AND VÖGTLE F. 1978. «Cascade»- and «Nonskid-Chain-like» Syntheses of Molecular Cavity Topologies. Synthesis 1978: 155-158.

CHEN HT, NEERMAN MF, PARRISH AR AND SIMANEK EE. 2004. Cytotoxicity, hemolysis, and acute in vivo toxicity of dendrimers based on melamine, candidate vehicles for drug delivery. J Am Chem Soc 126: 1004410048.

CHENG Y AND XU T. 2008. The effect of dendrimers on the pharmacodynamic and pharmacokinetic behaviors of noncovalently or covalently attached drugs. Eur J Med Chem 43: 2291-2297.

CHOI JS, NAM K, PARK JY, KIM JB, LEE JK AND PARK JS. 2004. Enhanced transfection efficiency of PAMAM dendrimer by surface modification with L-arginine. J Control Release 99: 445-456.

DAMIA G AND GARATTINI S. 2014. The pharmacological point of view of resistance to therapy in tumors. Cancer Treat Rev 40: 909-916.
DHANIKULA RS, ARGAW A, BOUCHARD JF AND HILDGEN P. 2008. Methotrexate loaded polyethercopolyester dendrimers for the treatment of gliomas: enhanced efficacy and intratumoral transport capability. Mol Pharm 5: 105-116.

DICHWALKAR T, BAPAT S, PANCHOLI P, YELLEPEDDI V K AND SEHDEV V. 2016. Abstract 2200: Omega-3 fatty acid conjugated paclitaxel dendrimers exhibit enhanced anticancer activity in various preclinical models of gastrointestinal cancers. Cancer Res 76(Supplement): 2200-2200.

DUNCAN R. 2003. The dawning era of polymer therapeutics. Nat Rev Drug Discov 2: 347-360.

DUNCAN R AND IZZO L. 2005. Dendrimer biocompatibility and toxicity. Adv Drug Delivery Rev 57: 2215-2237.

EL-SAYED M, GINSKI M, RHODES CAND GHANDEHARI H. 2002. Transepithelial transport of poly(amidoamine) dendrimers across Caco-2 cell monolayers. J Control Release 81: 355-365.

EL-SAYED M, KIANI MF, NAIMARK MD, HIKAL AH AND GHANDEHARI H. 2001. Extravasation of poly(amidoamine) (PAMAM) dendrimers across microvascular network endothelium. Pharm Res 18: 2328.

EL-SAYED M, RHODES CA, GINSKI M AND GHANDEHARI H. 2003. Transport mechanism(s) of poly (amidoamine) dendrimers across Caco-2 cell monolayers. Int J Pharm 265: 151-157.

FALCIANI C, FABBRINI M, PINI A, LOZZI L, LELLI B, PILERI S, BRUNETTI J, BINDI S, SCALI S AND BRACCI L. 2007. Synthesis and biological activity of stable branched neurotensin peptides for tumor targeting. Mol Cancer Ther 6: 2441-2448.

FERLAY J, SOERJOMATARAM I, DIKSHIT R, ESER S, MATHERS C, REBELO M, PARKIN DM, FORMAN D AND BRAY F. 2015. Cancer incidence and mortality worldwide: sources, methods and major patterns in GLOBOCAN 2012. Int J Cancer 136: 359-386.

FERRARI M. 2005. Cancer nanotechnology: opportunities and challenges. Nat Rev Cancer 5: 161-171.

FRECHET J M. 2002. Dendrimers and supramolecular chemistry. P Natl Acad Sci USA 99: 4782-4787.

FURGESON DY, DREHER MR AND CHILKOTI A. 2006. Structural optimization of a "smart" doxorubicinpolypeptide conjugate for thermally targeted delivery to solid tumors. J Control Release 110: 362-369.

GARTEL AL AND SHCHORS K. 2003. Mechanisms of c-myc-mediated transcriptional repression of growth arrest genes. Exp Cell Res 283: 17-21.

GERBER DE. 2008. Targeted therapies: a new generation of cancer treatments. Am Fam Physician 77: 311-319. 
GOLIAS CH, CHARALABOPOULOS A, CHARALABOPOULOS K. 2004. Cell proliferation and cell cycle control: a mini review. Int J Clin Pract 58: 1134-41.

GRAYSON SM AND FRECHET JM. 2001. Convergent dendrons and dendrimers: from synthesis to applications. Chem Rev 101: 3819-3868.

GREENFIELD RS, KANEKO T, DAUES A, EDSON MA, FITZGERALD KA, OLECH LJ, GRATTAN JA, SPITALNY GL AND BRASLAWSKY GR. 1990. Evaluation in vitro of adriamycin immunoconjugates synthesized using an acid-sensitive hydrazone linker. Cancer Res 50: 6600-6607.

GRINSTAFF MW. 2002. Biodendrimers: new polymeric biomaterials for tissue engineering. Chemistry 8: 28392846.

GURDAG S, KHANDARE J, STAPELS S, MATHERLY LH AND KANNAN RM. 2006. Activity of dendrimermethotrexate conjugates on methotrexate-sensitive and -resistant cell lines. Bioconjugate Chem 17: 275-283.

GUSTAFSON HH, HOLT-CASPER D, GRAINGER DW AND GHANDEHARI H. 2015. Nanoparticle Uptake: The Phagocyte Problem. Nano Today 10: 487-510.

HAAG R AND KRATZ F. 2006. Polymer therapeutics: concepts and applications. Angewandte Chem 45: 11981215.

HAWKER CJ AND FRECHET J. 1990. Preparation of polymers with controlled molecular architecture. A new convergent approach to dendritic macromolecules. J Am Chem Soc 112: 7638-7647.

HE X, ALVES CS, OLIVEIRA N, RODRIGUES J, ZHU J, BANYAI I, TOMAS H AND SHI X. 2015. RGD peptidemodified multifunctional dendrimer platform for drug encapsulation and targeted inhibition of cancer cells. Colloids Surf B Biointerfaces 125: 82-89.

HONG S, LEROUEIL PR, JANUS EK, PETERS JL, KOBER MM, ISLAM MT, ORR BG, BAKER JR JR AND BANASZAK HOLL MM. 2006. Interaction of polycationic polymers with supported lipid bilayers and cells: nanoscale hole formation and enhanced membrane permeability. Bioconjugate Chem 17: 728-734.

HUYNH NT, PASSIRANI C, SAULNIER P AND BENOIT JP. 2009. Lipid nanocapsules: a new platform for nanomedicine. Int J Pharm 379: 201-209.

IHRE HR, PADILLA DE JESUS OL, SZOKA FC JR AND FRECHET JM. 2002. Polyester dendritic systems for drug delivery applications: design, synthesis, and characterization. Bioconjugate Chem 13: 443-452.

JAIN RK. 2001. Delivery of molecular and cellular medicine to solid tumors. Adv Drug Deliver Rev 46: 149-168.

KAMINSKAS LM, MCLEOD VM, RYAN GM, KELLY BD, HAYNES JM, WILLIAMSON M, THIENTHONG N, OWEN DJ AND PORTER CJ. 2014. Pulmonary administration of a doxorubicin-conjugated dendrimer enhances drug exposure to lung metastases and improves cancer therapy. J Control Release 183: 18-26.

KESHARWANI P, XIE L, BANERJEE S, MAO G, PADHYE S, SARKAR FH AND IYER AK. 2015. Hyaluronic acidconjugated polyamidoamine dendrimers for targeted delivery of 3,4-difluorobenzylidene curcumin to CD44 overexpressing pancreatic cancer cells. Colloid Surfase B 136: 413-423.

KHANDARE JJ, JAYANT S, SINGH A, CHANDNA P, WANG Y, VORSA N AND MINKO T. 2006. Dendrimer versus linear conjugate: Influence of polymeric architecture on the delivery and anticancer effect of paclitaxel. Bioconjugate Chem 17: 1464-1472.

KIM YT AND ZHAO M. 2005. Aberrant cell cycle regulation in cervical carcinoma. Yonsei Med J 46: 597-613.

KOBAYASHI H AND BRECHBIEL MW. 2005. Nano-sized MRI contrast agents with dendrimer cores. Adv Drug Deliver Rev 57: 2271-2286.

KOST J AND LANGER R. 2001. Responsive polymeric delivery systems. Adv Drug Deliver Rev 46: 125-148.

LAROCQUE J, BHARALI DJ AND MOUSA SA. 2009. Cancer detection and treatment: the role of nanomedicines. Molr Biotechnol 42: 358-366.

LEE CC, CRAMER AT, SZOKA F JR AND FRECHET JM. 2006. An intramolecular cyclization reaction is responsible for the in vivo inefficacy and apparent $\mathrm{pH}$ insensitive hydrolysis kinetics of hydrazone carboxylate derivatives of doxorubicin. Bioconjugate Chem 17: 1364-1368.

LEE CC, MACKAY JA, FRECHET JM AND SZOKA FC. 2005. Designing dendrimers for biological applications. Nat Biotechnol 23: 1517-1526.

LEE JH, LIM YB, CHOI JS, LEE Y, KIM TI, KIM HJ, YOON JK, KIM K AND PARK JS. 2003. Polyplexes assembled with internally quaternized PAMAM-OH dendrimer and plasmid DNA have a neutral surface and gene delivery potency. Bioconjugate Chem 14: 1214-1221.

LEROUEIL PR, HONG S, MECKE A, BAKER JR JR, ORR G AND BANASZAK HOLL MM. 2007. Nanoparticle interaction with biological membranes: does nanotechnology present a Janus face? Accounts Chem Res 40: 335-342.

LI W, LIU D, ZHANG H, CORREIA A, MÄKILÄ E, SALONEN J, HIRVONEN J AND SANTOS HA. 2017. Microfluidic assembly of a nano-in-micro dual drug delivery platform composed of halloysite nanotubes and a $\mathrm{pH}$-responsive polymer for colon cancer therapy. Acta Biomater 48: 238-246.

LONG J, GUARI Y, GUÉRIN C AND LARIONOVA J. 2016. Prussian blue type nanoparticles for biomedical applications. Dalton T 45: 17581-17587.

LUO T, LOIRA-PASTORIZA C, PATIL HP, UCAKAR B, MUCCIOLI GG, BOSQUILLON C AND VANBEVER R. 2016. PEGylation of paclitaxel largely improves its safety 
and anti-tumor efficacy following pulmonary delivery in a mouse model of lung carcinoma. J Control Release 239: 62-71.

MAEDA H, WU J, SAWA T, MATSUMURA Y AND HORI K. 2000. Tumor vascular permeability and the EPR effect in macromolecular therapeutics: a review. J Control Release 65: 271-284.

MAINGI V, KUMAR MV AND MAITI PK. 2012. PAMAM dendrimer-drug interactions: effect of $\mathrm{pH}$ on the binding and release pattern. J Phys Chem B 116: 4370-4376.

MALIK N, EVAGOROU E G AND DUNCAN R. 1999. Dendrimer-platinate: a novel approach to cancer chemotherapy. Anti-Cancer Drugs 10: 767-776.

MALIK N, WIWATTANAPATAPEE R, KLOPSCH R, LORENZ K, FREY H, WEENER JW, MEIJER EW, PAULUS W AND DUNCAN R. 2000. Dendrimers: relationship between structure and biocompatibility in vitro, and preliminary studies on the biodistribution of 125I-labelled polyamidoamine dendrimers in vivo. $\mathrm{J}$ Control Release 65: 133-148.

MECKE A, LEE DK, RAMAMOORTHY A, ORR BG AND HOLL MM. 2005. Synthetic and natural polycationic polymer nanoparticles interact selectively with fluid-phase domains of DMPC lipid bilayers. Langmuir 21: 85888590.

MECKE A, MAJOROS IJ, PATRI AK, BAKER JR JR, HOLL MM AND ORR BG. 2005. Lipid bilayer disruption by polycationic polymers: the roles of size and chemical functional group. Langmuir 21: 10348-10354.

MEDINA SH AND EL-SAYED ME. 2009. Dendrimers as carriers for delivery of chemotherapeutic agents. Chem Rev 109: 3141-3157.

MISHRA V, GUPTA U AND JAIN N K. 2009. Surfaceengineered dendrimers: a solution for toxicity issues. $\mathrm{J}$ Biomat Sci-Polym E 20: 141-166.

MISRA R, ACHARYA S AND SAHOO SK. 2010. Cancer nanotechnology: application of nanotechnology in cancer therapy. Drug discov today 15: 842-850.

MORGAN MT, CARNAHAN MA, FINKELSTEIN S, PRATA CA, DEGORICIJA L, LEE SJ AND GRINSTAFF MW. 2005. Dendritic supramolecular assemblies for drug delivery. Chem Commun 34: 4309-4311.

MORGAN MT, CARNAHAN MA, IMMOOS CE, RIBEIRO AA, FINKELSTEIN S, LEE SJ AND GRINSTAFF MW. 2003. Dendritic molecular capsules for hydrophobic compounds. J Am Chem Soc 125: 15485-15489.

MORGAN MT, NAKANISHI Y, KROLL DJ, GRISET AP, CARNAHAN MA, WATHIER M, OBERLIES NH, MANIKUMAR G, WANI MC AND GRINSTAFF MW. 2006. Dendrimer-encapsulated camptothecins: increased solubility, cellular uptake, and cellular retention affords enhanced anticancer activity in vitro. Cancer Res 66: 11913-11921.
MORIKAWA A. 2016. Comparison of Properties among Dendritic and Hyperbranched Poly(ether ether ketone)s and Linear Poly(ether ketone)s. Molecules 21: 219-213.

MUKHERJEE J, WONG PT, TANG S, GAM K, COULTER A, BAKER JR JR AND CHOI SK. 2015. Mechanism of Cooperativity and Nonlinear Release Kinetics in Multivalent Dendrimer-Atropine Complexes. Mol Pharm 12: 4498-4508.

NEERMAN MF, CHEN HT, PARRISH AR AND SIMANEK EE. 2004. Reduction of drug toxicity using dendrimers based on melamine. Mol Pharm 1: 390-393.

NEWKOME GR, YAO Z, BAKER GR, AND GUPTA VK. 1985. Micelles. Part 1. Cascade molecules: a new approach to micelles. A [27]-arborol. J Org Chem 50: 2003-2004.

NGUYEN H, NGUYEN NH, TRAN N Q AND NGUYEN CK. 2015. Improved method for preparing Cisplatin-dendrimer nanocomplex and its behavior against NCI-H460 lung cancer cell. J Nanosci Nanotechno 15: 4106-4110.

NIEDERHAFNER P, SEBESTIK J AND JEZEK J. 2008. Glycopeptide dendrimers. Part II. Journal Pept Sci 14: 4465.

OLSON RD AND MUSHLIN PS. 1990. Doxorubicin cardiotoxicity: analysis of prevailing hypotheses. FASEB J 4: 3076-3086.

PADMA VV. 2015. An overview of targeted cancer therapy. Biomedicine 5: 1-6.

PATRI AK, KUKOWSKA-LATALLO JF AND BAKER JR JR. 2005. Targeted drug delivery with dendrimers: comparison of the release kinetics of covalently conjugated drug and non-covalent drug inclusion complex. Adv Drug Deliv Rev 57: 2203-2214.

PATRI AK, MYC A, BEALS J, THOMAS TP, BANDER NH AND BAKER JR JR. 2004. Synthesis and in vitro testing of J591 antibody-dendrimer conjugates for targeted prostate cancer therapy. Bioconjugate Chem 15: 11741181.

PEER D, KARP J M, HONG S, FAROKHZAD OC, MARGALIT R, AND LANGER R. 2007. Nanocarriers as an emerging platform for cancer therapy. Nat Nanotechnol 2: $751-760$.

QI R, GAO Y, TANG Y, HE RR, LIU TL, HE Y, SUN S, LI BY, LI YB AND LIU G. 2009. PEG-conjugated PAMAM dendrimers mediate efficient intramuscular gene expression. AAPS J 11: 395-405.

RYAN KM, PHILLIPS AC AND VOUSDEN KH. 2001. Regulation and function of the p53 tumor suppressor protein. Curr Opin Cell Biol 13: 332-7.

ROBERTS JC, BHALGAT MK AND ZERA RT. 1996. Preliminary biological evaluation of polyamidoamine (PAMAM) Starburst dendrimers. J Biomed Mater Res 30: 53-65.

ROSS JF, CHAUDHURI PK AND RATNAM M. 1994. Differential regulation of folate receptor isoforms in 
normal and malignant tissues in vivo and in established cell lines. Physiologic and clinical implications. Cancer 73 2432-2443.

SAMPATHKUMAR SG AND YAREMA KJ. 2005. Targeting cancer cells with dendrimers. Chem Biol 12: 5-6.

SATSANGI A, ROY SS, SATSANGI RK, TOLCHER AW, VADLAMUDI RK, GOINS B AND ONG JL. 2015. Synthesis of a novel, sequentially active-targeted drug delivery nanoplatform for breast cancer therapy. Biomaterials 59: 88-101.

SEBESTIK J, NIEDERHAFNER P AND JEZEK J. 2011. Peptide and glycopeptide dendrimers and analogous dendrimeric structures and their biomedical applications. Amino Acids 40: 301-370.

SEIB FP, JONES AT AND DUNCAN R. 2007. Comparison of the endocytic properties of linear and branched PEIs, and cationic PAMAM dendrimers in B16f10 melanoma cells. J Control Release 117: 291-300.

SHMEEDA H, MAK L, TZEMACH D, ASTRAHAN P, TARSHISH M AND GABIZON A. 2006. Intracellular uptake and intracavitary targeting of folate-conjugated liposomes in a mouse lymphoma model with up-regulated folate receptors. Mol Cancer Ther 5: 818-824.

SINGH P, GUPTA U, ASTHANA A AND JAIN NK. 2008. Folate and folate-PEG-PAMAM dendrimers: synthesis, characterization, and targeted anticancer drug delivery potential in tumor bearing mice. Bioconjugate Chem 19: 2239-2252.

STREBHARDT K AND ULLRICH A. 2008. Paul Ehrlich's magic bullet concept: 100 years of progress. Nat Rev Cancer 8: 473-480.

SVENSON S. 2009. Dendrimers as versatile platform in drug delivery applications. Eur J Pharm Biopharm 71: 445-462.

SVENSON S AND TOMALIA DA. 2005. Dendrimers in biomedical applications--reflections on the field. Adv Drug Deliver Rev 57: 2106-2129.
TEKADE RK, KUMAR PV AND JAIN NK. 2009. Dendrimers in oncology: an expanding horizon. Chem Rev 109: 49-87.

TOMALIA D, BAKER H, DEWALD J, HALL M, KALLOS G, MARTIN S, ROECK J, RYDER J AND SMITH P. 1985. A New Class of Polymers: Starburst-Dendritic Macromolecules. Polym J 17: 117-132.

TOMALIA DA, BAKER H, DEWALD J, HALL M, KALLOS G, MARTIN S, ROECK J, RYDER J AND SMITH P. 1986. Dendritic macromolecules: synthesis of starburst dendrimers. Macromolecules 19: 2466-2468.

TOMALIA DA, REYNA LA AND SVENSON S. 2007. Dendrimers as multi-purpose nanodevices for oncology drug delivery and diagnostic imaging. Biochemical Soc T 35: 61-67.

URZUA JI, REGUEIRA MA, LAZZARI M AND TORNEIRO M. 2016. Shape-persistent fluorescent tetraphenylmethane dendrimers. Polym Chem 7: 5641-5645.

VALDES O, VILOS V AND DURÁN-LARA E. 2016. Techniques of Structural Characterization of Dendrimers. Curr Org Chem 20: 2591-2605.

WOLINSKY JB AND GRINSTAFF MW. 2008. Therapeutic and diagnostic applications of dendrimers for cancer treatment. Adv Drug Deliver Rev 60: 1037-1055.

XU H, REGINO CA, KOYAMA Y, HAMA Y, GUNN A J, BERNARDO M, KOBAYASHI H, CHOYKE PL AND BRECHBIEL MW. 2007. Preparation and preliminary evaluation of a biotin-targeted, lectin-targeted dendrimerbased probe for dual-modality magnetic resonance and fluorescence imaging. Bioconjugate Chem 18: 1474-1482.

YELLEPEDDI VK, KUMAR A AND PALAKURTHI S. 2009. Surface modified poly(amido)amine dendrimers as diverse nanomolecules for biomedical applications. Expert Opin Drug Deliv 6: 835-850.

YIN X, HOFFMAN AS AND STAYTON PS. 2006. Poly(N-isopropylacrylamide-co-propylacrylic acid) copolymers that respond sharply to temperature and $\mathrm{pH}$. Biomacromolecules 7: 1381-1385. 